\title{
Víctor Andrés Belaunde: ¿antimoderno o ultramoderno?
}

\author{
Carlos Masías Vergara \\ Universidad de Piura
}

Posturas frente a la modernidad. ¿Pertenece Víctor Andrés Belaunde a una corriente de tradición moderna, como parece sugerir López Soria en su interesante obra Adiós a Mariátegui? ¿No debería considerársele, como por mucho tiempo se ha hecho, como un autor contrario a la modernidad, un conservador reaccionario producto de su conversión al catolicismo? Dar respuesta a estas preguntas no resulta del todo fácil. En primer lugar, deberíamos tener en claro cuáles son las posturas que se han adoptado frente a la modernidad, para así poder delimitar la postura del propio Belaunde.

La crítica a la modernidad no es algo de los últimos tiempos, sino que ya desde sus albores el proyecto moderno fue objeto de críticas y tomas de postura. Sin un afán de exhaustividad, se pueden distinguir tres posturas frente a ella. La primera es la que surge en la conocida querella de los antiguos y los modernos. El antiguo es -frente al moderno- el espíritu nostálgico atrapado en la memoria de un tiempo que no regresa. Es la abeja -metáfora genial de Swiftcuya producción sale de haber ido a libar en los jardines de la memoria frente a una araña moderna, cuya producción sale de sus propias entrañas, de su 'yo'. Según Fumaroli, para Swift, el cartesianismo, al igual que las arañas, saca todo de sí mismo.

extraen de sus negras vísceras un hilo abstracto, y con ese hilo componen unas telas geométricas tendidas sobre el mundo: son trampas mortales. (...) La metafísica y la ciencia de Descartes han provisto al «yo» que canonizan de un método para sustituir el mundo creado por un mundo construido, los dones de las Musas y de la Memoria por las conquistas de la ciencia. ${ }^{1}$

Y aun cuando la querella terminó con el fin del antiguo régimen, la crítica a la modernidad persistió en otros autores. Así, pues, en tiempos relativamente

1 Marc Fumaroli, Las abejas y las arañas. La querella de los antiguos y los modernos. Barcelona, Acantilado, 2008, p. 14. Acerca de la crítica de Swift a la modernidad puede verse también Allan BLoom, Gigantes y enanos: la tradición ética y politica de Sócrates a John Rawls. Barcelona, Gedisa, 1999, pp. 43-68.

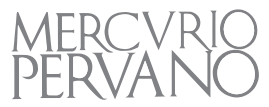


recientes, Antoine de Compagnon ha llamado la atención sobre otra postura histórica frente a la modernidad: los antimodernos. Compagnon se encarga de diferenciar a los antimodernos de los tradicionalistas y los conservadores: "los antimodernos -no los tradicionalistas por tanto, sino los antimodernos auténticos- no serían más que los modernos, los verdaderos modernos, que no se dejan engañar por lo moderno, que están siempre alertas". ${ }^{2} \mathrm{O}$ bien, como dirá más adelante, el antimoderno no sería más que el "moderno arrastrado por la corriente de la historia, pero incapaz de guardar luto por el pasado". ${ }^{3}$ El antimoderno es, pues, el moderno consciente de la insuficiencia de la modernidad, pero incapaz de dar con una salida; de ahí su actitud reaccionaria y pesimista. En el ambiente intelectual peruano, destaca como pensador antimoderno el católico José de la Riva-Agüero y Osma. ${ }^{4}$

A inicios del siglo $X X$, en el ámbito intelectual católico, hubo también una preocupación por tomar una posición frente a la modernidad. ${ }^{5} \mathrm{Y}$ aunque en una visión simplista se puede llegar a pensar que la actitud fue únicamente de rechazo a la modernidad y un soñar con una vuelta a una sociedad religiosa como la medieval, lo cierto es que también en el ámbito católico cabe distinguir posturas. Interesa destacar una, que fue perfilada por Maritain ${ }^{6}$ a lo largo de sus obras. En Antimodernos, una obra publicada en 1922, afirma: "Lo que aquí llamo antimoderno hubiera podido ser llamado perfectamente ultramoderno". El ultramodernismo del filósofo francés no significa, como podría hacer pensar su orientación tomista, un intento por volver al pasado, un querer reponer la cosmovisión medieval. El propio Maritain salió al frente de este tipo de juicios sobre su propio pensamiento. En una obra posterior, Tres reformadores, en la que realizaba un estudio crítico de lo que consideraba los tres pensadores que dieron inicio a la modernidad, señalaba: "Acaso volverá a decirse que yo pretendo condenar en bloque tres siglos de historia humana y 'volver a la Edad Media'. Nada más falso. Este libro está vuelto hacia el futuro, hacia el inmenso futuro que exige de nosotros una mirada clara y nuevas fuerzas. (...) En una palabra: hoy no se puede tomar el propio impulso más que yendo muy hacia atrás en el

\footnotetext{
2 Antoine Compagnon, Los antimodernos. Barcelona, Acantilado, 2005, p. 12.

Antoine Compagnon, Los antimodernos, p. 21.

4 Francisco Bobadilla, "José de la Riva-Agüero y Osma o el intelectual antimoderno", en Mercurio Peruano, 502, 2007, pp. 46-81.

5 Sobre el renacimiento intelectual católico europeo de inicios del siglo pasado puede consultarse Joseph PeARce, Escritores conversos: la inspiración espiritual en una época de incredulidad. Madrid, Palabra, 2009; y Richard Griffiths, The Pen and the Cross: Catholicism and English Literature (1850-2000). New York, Continuum International, 2010.

6 La postura de Maritain resulta interesante tanto porque fue un referente en el mundo intelectual católico de inicios y mediados del siglo pasado como porque Belaunde estuvo, en un momento de su vida, próximo a su magisterio. En sus memorias cuenta haber asistido a algunas clases de Maritain en Francia.
}

7 Jacques Maritain, Antimoderne, p. 102. Citado por Antoine Compagnon, Los antimodernos, p. 13.

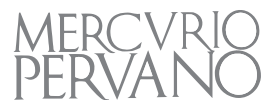


tiempo; pero no vamos hacia atrás sino para saltar mejor". ${ }^{8}$ Libros posteriores como Humanismo integral, tan duramente incomprendido por el catolicismo español, ${ }^{9}$ es quizá un ejemplo de ese espíritu ultramoderno de Maritain.

\section{Belaunde y la modernidad}

Aclaradas las posibles posturas frente a la modernidad, hay que señalar que la actitud de Belaunde frente a la modernidad no resulta a primera vista clara, pues sin ignorar sus múltiples críticas a diversos aspectos de la modernidad, hay también en su pensamiento juicios sobre la modernidad y valoraciones de carácter existencial de tono positivo, que revelan un reconocimiento del pensamiento moderno. Piénsese, por ejemplo, en las páginas de sus memorias, ${ }^{10}$ donde narra su conversión desarrollada de la mano de la lectura de filósofos modernos como Descartes, Spinoza, Pascal y Kant. De ahí que su filosofía del temple, esa antropología de corte existencial, haya sido elaborada en diálogo con Spinoza -en tanto que modelo de la serenidad- y Pascal -filósofo de la inquietud- para terminar coronándola con la plenitud que descubre en san Agustín, pero no solo en él. Del propio Kant llegará a decir, en una obra ya tardía como es La síntesis viviente, que "por la crítica de la razón práctica, y a través de caminos distintos de los que siguieron Agustín y Tomás, es [Kant] en la cultura occidental el último representante de la filosofía de la plenitud". ${ }^{11}$

Mi objetivo será intentar establecer cuál es la postura de Belaunde frente a la modernidad. Para poder aclarar esa postura, leeré una de las obras a la que menos atención se le ha prestado: El Cristo de la fe y los cristos literarios (1936).$^{12} \mathrm{La}$ elección de esta obra en particular, a pesar de su olvido, se justifica por varias razones, y en primer lugar, porque la conversión religiosa de Belaunde no es un hecho epidérmico. Su vuelta al catolicismo no fue buscar un refugio ante su fracaso político, como alguna vez se ha sugerido, sino que fue un hecho radical. Por ello resulta de interés e importancia estudiar las ideas que subyacen en una de sus pocas obras de tema religioso y que está centrada en la figura de Cristo. Segundo, a pesar de estar centrada en la figura de Cristo, Belaunde reconoce en el prólogo: "No obstante de no representar mi trabajo ningún aporte nuevo para la cristología, en el terreno técnico, él se justifica desde el punto de vista de la

\footnotetext{
8 Jacques Maritain, Tres reformadores. Madrid, Encuentro, 2006, pp. 7-8.

9 Sobre la recepción de Maritain por parte de la intelectualidad católica de su época puede verse el artículo de Carlos DíAz, "La recepción del personalismo en España”, en Ars Brevis. Anuario de la cátedra Ramon Llull Blanquerna, 12, 2006, pp. 195-217.

10 Cfr. Víctor Andrés Belaunde, Trayectoria y destino: memorias completas. Lima, Ediventas, 1997, tomo 2, pp. 501-508.

11 Víctor Andrés Belaunde, La sintesis viviente, p. 43.

12 Víctor Andrés Belaunde, El Cristo de la fe y los cristos literarios. Lima, Lumen, 1936. Cito entre paréntesis las páginas de esta primera edición.
}

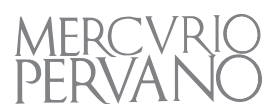


filosofía general y, sobre todo, de la sociología religiosa" (XI). Tercero, y la razón que más nos interesa para el tema de esta exposición, la comparación de la visión tradicional que de Cristo se ha tenido con las distintas visiones de Cristo que, escritores y filósofos, fueron proponiendo a lo largo de la modernidad, "reviste una excepcional importancia -dirá Belaunde-, porque encierra la clave de la crisis del espíritu moderno" (XI). Creo que esta última afirmación de Belaunde justifica que podamos realizar una lectura filosófica de esa obra, sacando a la luz la crítica a la modernidad que contiene. Nos detendremos en tres aspectos claves: el aspecto metafísico, por el cual Belaunde entiende a la modernidad como una desintegración de la síntesis viviente; el gnoseológico, en el que se critica la racionalidad analítica; y el ético, en el que se esboza una ética de la otredad a partir del mandamiento de amar al prójimo.

\section{Modernidad y desintegración}

Los dos. Como el título de la obra lo indica, toda la exposición de Belaunde se articula en torno a una distinción principal: la distinción del Cristo de la fe de los cristos literarios. El Cristo de la fe es el cristo objetivo mientras que el cristo de la literatura sería producto de la subjetividad. Resulta, pues, que lo que se está contraponiendo es la experiencia objetiva frente a una experiencia subjetiva. El Cristo de la fe, en tanto que experiencia objetiva, está fuera del sujeto, y se refiere "a una persona, a una doctrina y a una continuidad de su obra; en síntesis, a una realidad fuera de nosotros y superior a nosotros"(3-4). A diferencia de este, los cristos de la literatura son puramente subjetivos, son accidentes de nuestra vida intelectual, una pura proyección de nuestra psique.

Lo objetivo es lo dado a la conciencia. Esta no lo crea sino que "lo acepta simplemente y se lo asimila en su total esencia y en sus rasgos inmutables" (4). Lo subjetivo es "el resultado de una creación o apreciación individual" (4), y en esa medida lo puramente subjetivo es un encerrarse en sí mismo, un puro ejercicio de egocentrismo. Por otra parte, cuando la conciencia se abre objetivamente a lo dado por la realidad, en la aceptación de lo dado constituye también su propia subjetividad, una subjetividad mucho más profunda que la anterior, en la medida en que es "un valor íntimo de arraigada subjetividad en cada uno de nosotros" (4). Pues en la medida en que se abre a la realidad, se abre también al mundo de la libertad moral -que Belaunde cree que se revela plenamente en la figura de Cristo-, en cambio la subjetividad cerrada en sí misma ha roto con la realidad, y en esa medida lo que asume como dato son los procesos mentales conscientes, pero también los inconscientes: resentimientos, complejos, temores...

Así, los Cristos subjetivos, sin relación a un mensaje tradicional, representarán racionalizaciones o sublimaciones de nuestros impulsos y de nuestros intereses. (5)

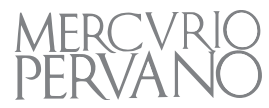


Es decir, la vía de la subjetividad es la vía que recorre el camino egolátrico moderno. Lo que está en pugna en los dos Cristos son dos modos de entender el pensamiento. El pensar objetivo, en el que la conciencia se abre a lo dado por la realidad, y únicamente a partir de lo dado constituye lo subjetivo; o el pensar subjetivo, que Belaunde califica de egocéntrico, "una cerrazón, de progresiva limitación individual". (5)

\section{Desintegración de la síntesis}

Para entender lo que Belaunde señala a lo largo de la obra, primero debemos aclarar muy grosso modo la manera como Belaunde considera a la realidad desde una dimensión metafísica. ${ }^{13}$ Belaunde entiende la realidad desde un modelo dinámico de jerarquía de formas, en el que distingue tres niveles de realidad: la materia, la vida y el espíritu.

El ámbito de lo material es el ámbito de la cantidad, y los elementos de este nivel están determinados por la causalidad que se desarrolla cíclicamente. La síntesis de la vida es la propia del elan creador, del impulso espontáneo y creador que se encarna "en la lucha constante, ineludible y necesaria. La vida se mantiene asimilando y aniquilando otras vidas" (118). La vida, en su impulso autoafirmador, establece un proceso de selección natural por el que triunfa el más fuerte. Por último, el espíritu es el ámbito de la libertad y unidad. La libertad es sobre todo moralidad: son los ideales, el deber y el amor, que el hombre descubre y que con su acción introduce en el mundo, y bajo los cuales subsume los niveles inferiores.

La existencia humana -y el mundo humano en el que se desarrolla- está conformada por lo material y lo vital reorientados por la vida del espíritu. "La materia y la vida son asumidas y vivificadas por el Espíritu" (101). Frente a esta visión de la realidad última, la modernidad aparece ante Belaunde como un tiempo de crisis, porque supone la desintegración de la síntesis vital. Esa desintegración ha consistido en la exaltación ya sea de la materia o la vida junto al olvido del espíritu. El olvido del espíritu se ha manifestado históricamente en Occidente en el olvido del Cristo objetivo, y, por ende, la deriva de los cristos subjetivos no es otra cosa que aquel humanismo antropocéntrico, que ha hipertrofiado la dimensión material y vital del hombre.

La rebeldía de la modernidad ha consistido, para Belaunde, en negar la dimensión espiritual de la realidad. Pero esta negación no se ha hecho de modo explícito, sino por la vía sutil de confundir el espíritu con la materia o la vida. Así, para Belaunde, “El mundo moderno vive, desde el Renacimiento y la Reforma, bajo un signo vital. La rebeldía de la razón es vitalismo; lo es también

13 Una exposición más detallada de la metafísica de Belaunde la he trabajado en “Víctor Andrés Belaunde y la metafísica de la síntesis viviente", en Mercurio Peruano, 523, 2011, pp. 89-103.

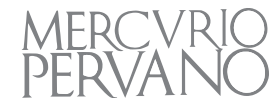


la rebeldía del sentimiento que se refleja en el Romanticismo. El absolutismo es una forma de vitalismo cuando extrema la voluntad de poder. Y el capitalismo no es sino la exaltación vital aplicada a la economía" (192). Es decir, en ninguno de estos se hace un rechazo explícito de la dimensión espiritual, pero los valores y deberes que se enuncian muchas veces no son más que sublimaciones del ciego impulso vital. El espíritu dejó de ser entendido como una dimensión superior respecto de lo vital, y pasó a ser entendido como una continuidad de la vida. El principio de utilidad en la política y el principio de laissez faire y laissez passer en lo económico es un ejemplo de ello. "El hombre económico -explica Belaunde-, que se movía en el marco humano de las corporaciones, se libera de ellas; pero creado el mecanismo, y el capitalismo llega a ser como la máquina -y aún menos que la máquina- una mercancía" (213).

Belaunde recorre la historia de la modernidad señalando como la reforma que en lugar de traer una etapa de libertad religiosa sometió la religión al Estado. El Renacimiento no trajo una nueva libertad espiritual, sino la anarquía mental. Y la revolución del siglo XVIII, por su raigambre roussoniana, sustituyó un absolutismo monárquico por otro muy distinto, el absolutismo de la voluntad colectiva o de las mayorías: "La tiranía del monarca es reemplazada por la voluntad omnímoda de las asambleas, de los comités y de la burocracia" (213-214). Todo esto va culminando -señala Belaunde- en la constitución de un hombre nuevo: el hombre masa que es capaz de aniquilar en segundos la larga tradición espiritual. De esto, en la actualidad, tenemos muchos ejemplos.

\section{Crítica a la razón moderna}

La razón moderna, separada de la guía moral del espíritu, devino en una razón instrumental, que permitió el dominio sobre la naturaleza. Para esa labor, ya no era necesaria una elevada razón metafísica, sino bastaba con la razón analítica de las ciencias empíricas. Sin embargo el problema con la razón analítica es que desvirtúa la realidad como unidad. Belaunde grafica ese límite del análisis con el siguiente ejemplo: "El brillante es luz mientras se mantiene íntegro; el mismo brillante, pulverizado y deshecho, contendrá los mismos elementos químicos, la misma cantidad de materia, mas ya no reflejará la luz del sol. Esos elementos impalpables de luminosidad y de fuego se escaparán siempre a los analistas que carecen de visión profunda de la naturaleza de las cosas, de la verdadera perspectiva filosófica y de una amplia mirada sobre el panorama" (180).

Una razón analítica orientada a lo instrumental, una razón incapaz de aprehender lo esencial de la realidad, se torna inhumana cuando intenta comprender al hombre. La razón analítica, al encontrarse escindida de la dimensión espiritual, subsumirá al hombre en el dinamismo causal de la materia, y hará del hombre un esclavo de ese dinamismo.

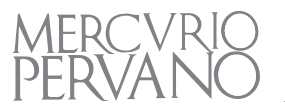


La inteligencia ha dominado las fuerzas físicas; pero, al romper sus lazos con un mundo superior, ha negado el Espíritu y la fuente misma de su fecundidad creadora y ordenadora. La inteligencia está destinada a servir a los dictados del Espíritu o las rebeldías de la Vida" (219).

\section{Ética de la otredad}

En el ámbito ético, el olvido del espíritu ha supuesto la pérdida de la noción de filiación divina, que -piensa Belaunde- era el único fundamento de la fraternidad humana. Producto de esta pérdida, las relaciones humanas se entenderán a partir de la pura biología o materia. "Suprimamos esa fraternidad y no quedarán sino diferencias biológicas y psíquicas, instintos de lucha, oposición de intereses, contrastes de tendencias y de ambiciones" (22).

El mandamiento del amor al prójimo supone una superación de las limitaciones individuales, tanto de orden biológico como material. "¿Y quién es el prójimo? En el Evangelio, el prójimo no es ni el hermano por la sangre, por la raza o por la patria, es el desconocido y, sobre todo, el desconocido en miseria y en dolor" (23). Prójimo, por lo tanto, alude no a una proximidad material, afectiva o comunitaria, sino a la radical proximidad de la fraternidad en la filiación divina, desde la cual debemos amar incluso a nuestros enemigos. La ética del prójimo es una ética de la otredad, donde uno siente el imperioso deber fraterno de asistir al otro en su necesidad sin esperar ninguna retribución, y que debe centrarse en el más necesitado.

Si la generosidad y el amor no buscan la recompensa establecerán, sí, una diferenciación, pero con una original tabla de valores. Las muestras de afecto y los homenajes deben ser, principalmente, para los pobres, para los desheredados. Si alguna preferencia cabe en nuestro amor será la preferencia fundada en el dolor y en la miseria humanos. (24)

\section{Conclusión}

Recapitulando lo brevemente expuesto, las ideas de Belaunde, por lo menos en esta obra, reflejan un fuerte ajuste de cuentas sobre la modernidad. Sin embargo, aunque realiza una dura crítica de la modernidad por el olvido de la raíz cristiana de Occidente, no propone Belaunde una vuelta a la medievalidad o una nueva forma de antiguo régimen. Belaunde considera que la fuerza espiritual del cristianismo puede volver a plantear una nueva civilización, y en ese sentido su crítica a la modernidad supone un intento de superarla, de ir más allá de ella. Belaunde es un ultramoderno. 


\section{Bibliografía}

Belaunde, Víctor Andrés, El Cristo de la fe y los cristos literarios. Lima, Editorial Lumen, 1936.

_. Trayectoria y destino: memorias completas. Lima, Ediventas, 1967.

_. La síntesis viviente. Palabras de fe. Incluidas en Obras completas, V.6 Lima, Pontificia Universidad Católica del Perú, 1993.

BLoom, Allan, Gigantes y enanos: la tradición ética y política de Sócrates a John Rawls. Barcelona, Gedisa, 1999.

Bobadilla, Francisco, “José de la Riva-Agüero y Osma o el intelectual antimoderno”, en Mercurio Peruano, 502, 2007, pp. 46-81.

Compagnon, Antoine, Los antimodernos. Barcelona, Acantilado, 2005.

DíAz, Carlos, “La recepción del personalismo en España”, en Ars Brevis. Anuario de la cátedra Ramon Llull Blanquerna, 12, 2006, pp. 195-217.

Fumaroli, Marc, Las abejas y las arañas. La querella de los antiguos y los modernos. Barcelona, Acantilado, 2008.

Griffiths, Richard. The Pen and the Cross: Catholicism and English Literature (18502000). New York, Continuum International, 2010.

López Soria, José Ignacio, Adiós a Mariátegui. Pensar el Perú en perspectiva postmoderna. Lima, Fondo Editorial del Congreso del Perú, 2007.

Maritain, Jacques, Tres reformadores. Madrid, Encuentro, 2006.

Masías Vergara, Carlos, “Víctor Andrés Belaunde y la metafísica de la síntesis viviente", en Mercurio Peruano, 523, 2011, pp. 89-103.

PeArce, Joseph, Escritores conversos: la inspiración espiritual en una época de incredulidad, Madrid, Palabra, 2009. 